Supporting Information for

\title{
Electrical Transport in Polyaniline-Barium Ferrite Nanocomposites with Negative Giant Magnetoresistance
}

Jingyi Cai, ${ }^{1}$ Wenxuan Wang, ${ }^{1}$ Duo Pan, ${ }^{2,3}$ David P. Young, ${ }^{4}$ Hongbo Gu, ${ }^{1, *}$ Zhanhu Guo ${ }^{2}$

${ }^{1}$ Shanghai Key Lab of Chemical Assessment and Sustainability, School of Chemical Science and Engineering, Tongji University, Shanghai 200092, People's Republic of China

${ }^{2}$ Integrated Composites Lab (ICL), Department of Chemical \& Biomolecular Engineering University of Tennessee, Knoxville, Tennessee, 37966, United States

${ }^{3}$ Key Laboratory of Materials Processing and Mold (Zhengzhou University), Ministry of Education, National Engineering Research Center for Advanced Polymer Processing Technology, Zhengzhou University, Zhengzhou, China

${ }^{4}$ Department of Physics and Astronomy, Louisiana State University, Baton Rouge, Louisiana, 70803, United States

Corresponding Author: hongbogu2014@tongji.edu.cn, 
S1. The fitted lines of $\mathrm{M}-\mathrm{H}^{-1}$ nearly $2 \mathrm{~T}$
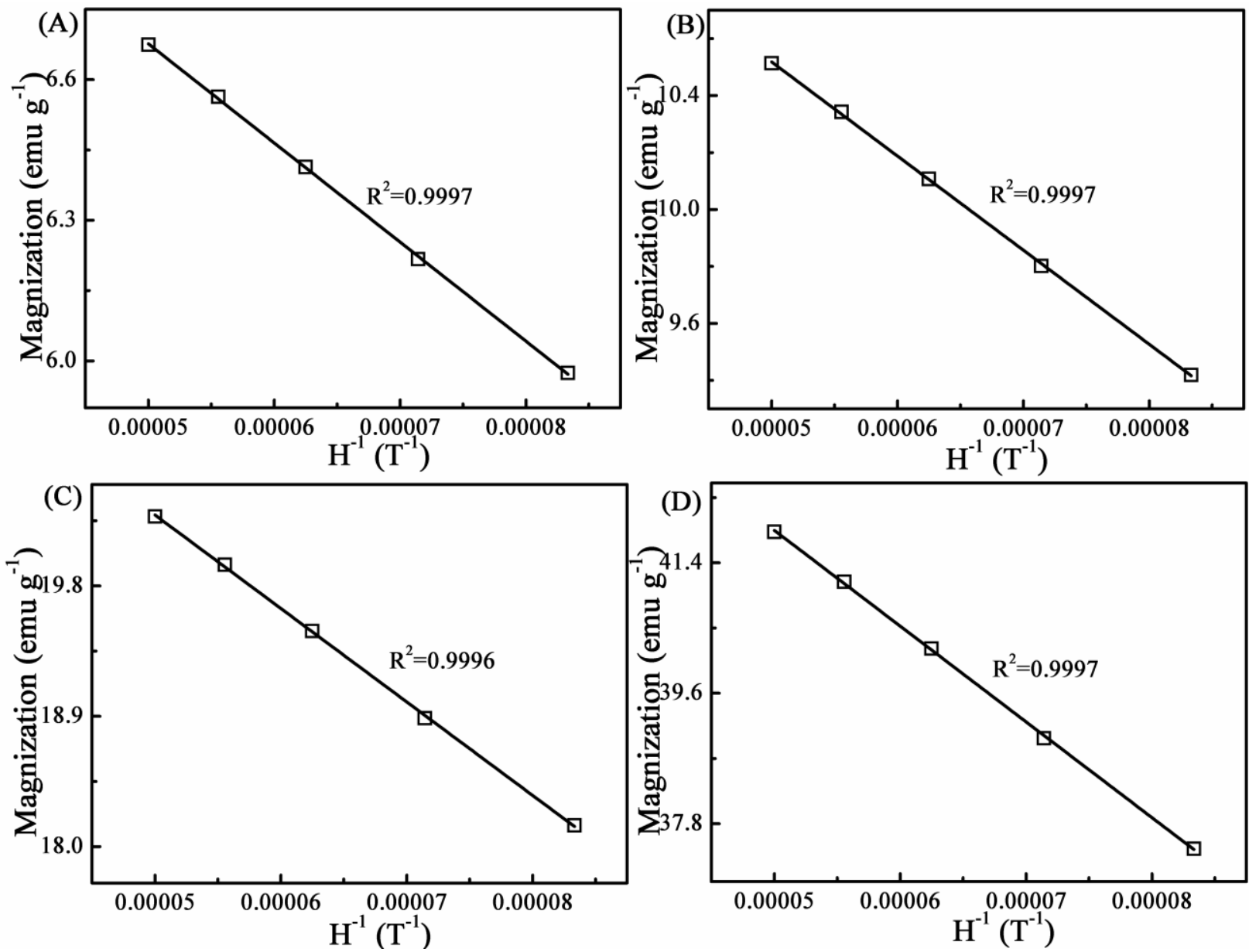

Figure S1. The fitting lines of $\mathrm{M}-\mathrm{H}^{-1}$ nearly $2 \mathrm{~T}$ for $\mathrm{BaFe}_{12} \mathrm{O}_{19} / \mathrm{PANI}$ nanocomposites with a loading of (a)10, (b) 20, and (c) 30 wt \% and pure $\mathrm{BaFe}_{12} \mathrm{O}_{19}$ nanoparticles. 


\section{S2. SEM images and TEM image of $\mathrm{PANI} / \mathrm{BaFe}_{12} \mathrm{O}_{19}$ nanocomposites}
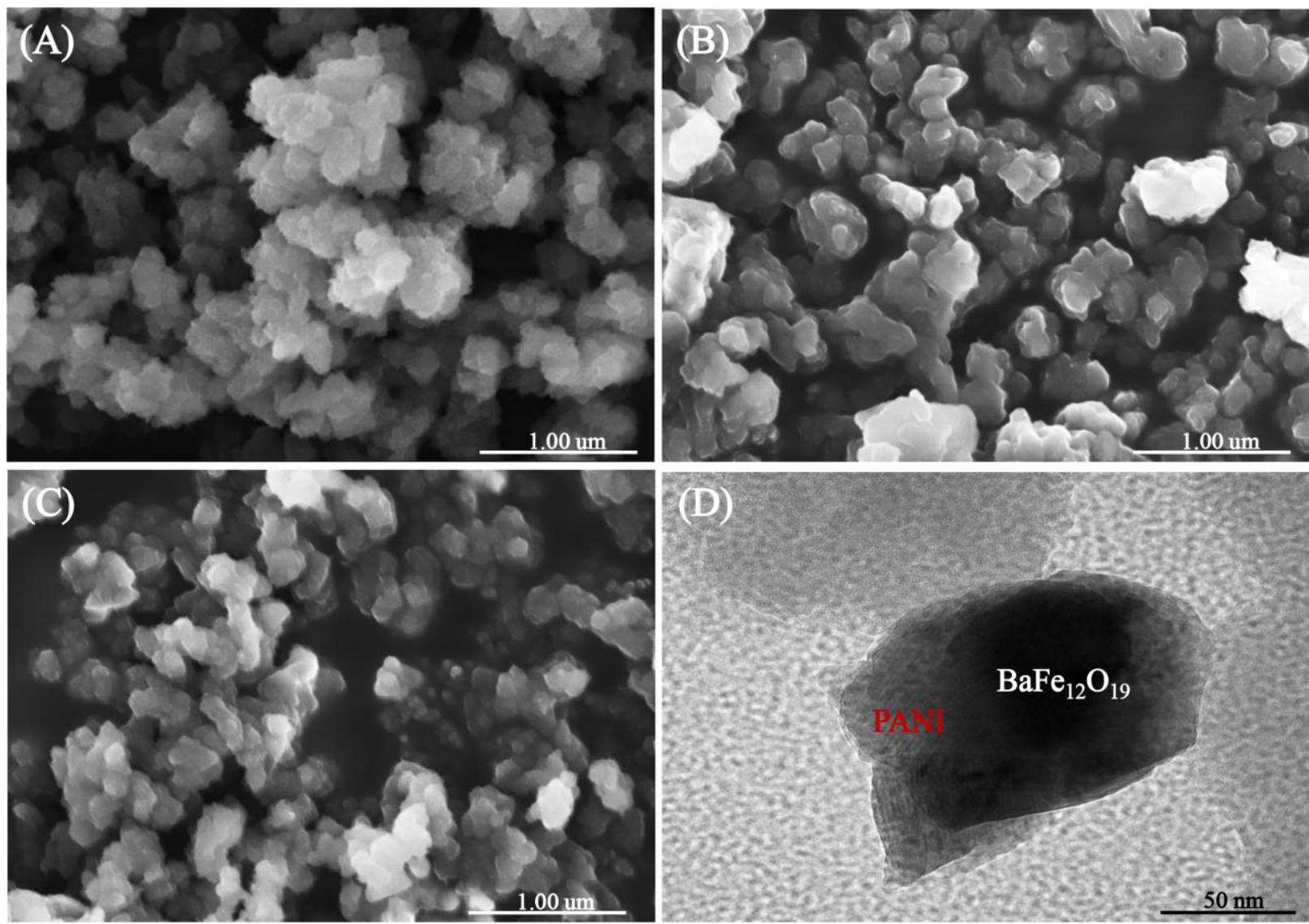

Figure S2. SEM images of $\mathrm{BaFe}_{12} \mathrm{O}_{19} / \mathrm{PANI}$ with a loading of (a) 10, (b) 30, (c) $40 \mathrm{wt} \%$ and (d) TEM image of $20 \mathrm{wt} \% \mathrm{BaFe}_{12} \mathrm{O}_{19} / \mathrm{PANI}$ nanocomposites. 


\section{S3. The electron diffraction pattern of $20 \mathrm{wt} \% \mathrm{BaFe}_{12} \mathrm{O}_{19} / \mathrm{PANI}$ nanocomposites}

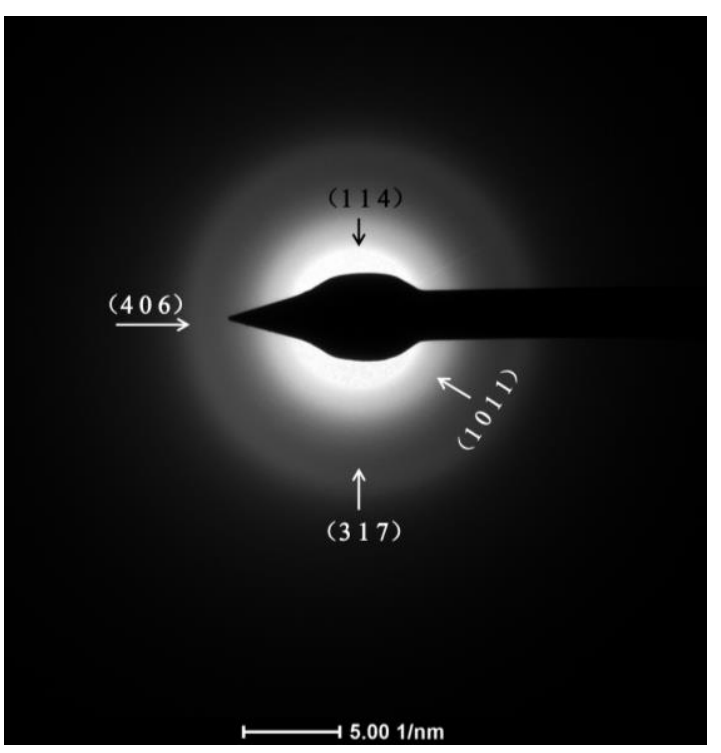

Figure S3. The electron diffraction pattern for $\mathrm{BaFe}_{12} \mathrm{O}_{19} / \mathrm{PANI}$ nanocomposites with a loading of $20 \mathrm{wt} \%$.

In the Figure S3, it's observed that there are four planes, which is consisted with the (114), (1011), (406) and (317) crystallographic planes, in the diffraction pattern of $\mathrm{BaFe}_{12} \mathrm{O}_{19}$ (PDF\#27-1029), Figure 1B. 


\section{S4. Calculation of band gaps of $\mathrm{PANI} / \mathrm{BaFe}_{12} \mathrm{O}_{19}$ nanocomposites}
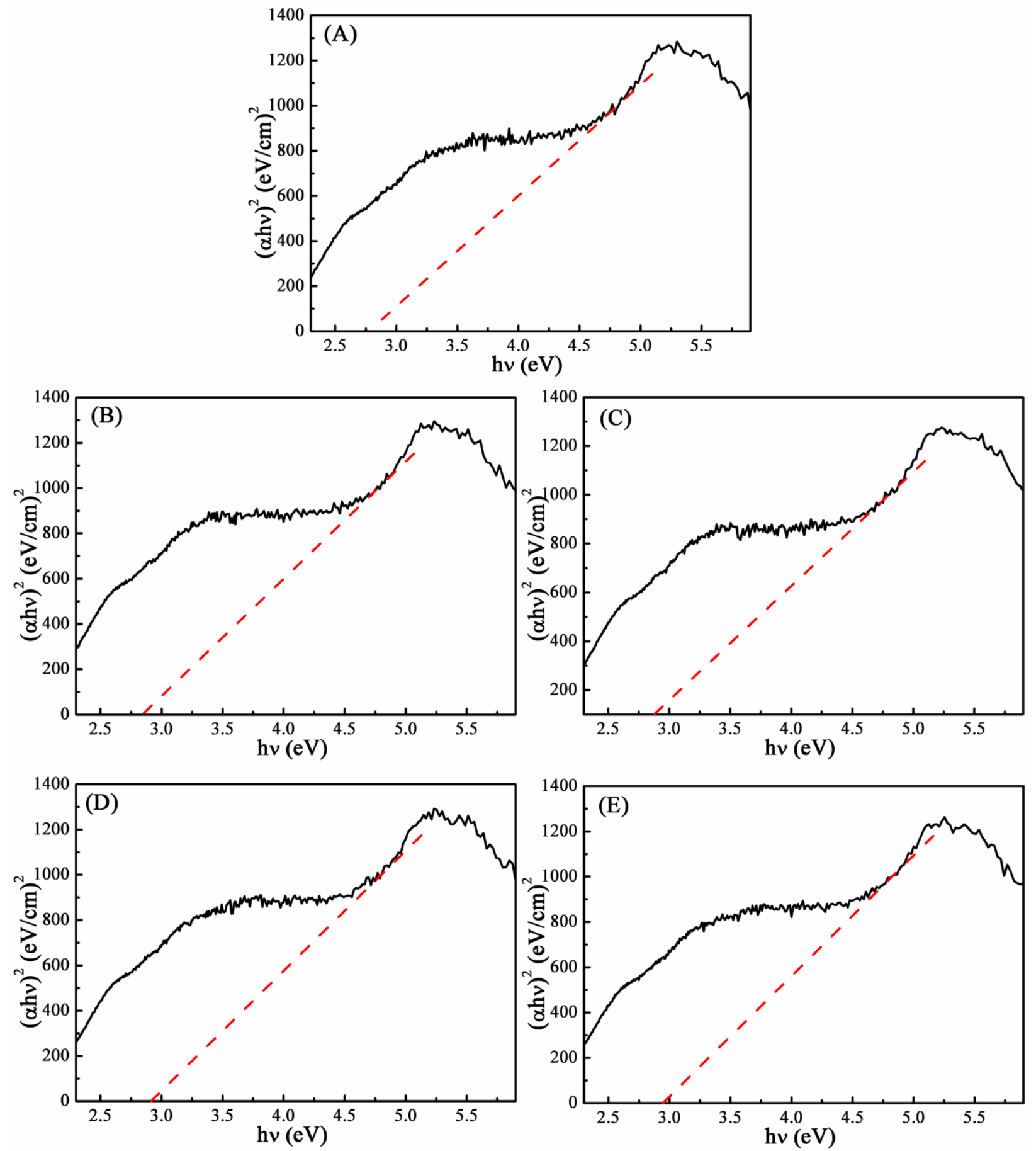

Figure S4. Calculation of band gaps for (A) pure PANI, and $\mathrm{BaFe}_{12} \mathrm{O}_{19} / \mathrm{PANI}$ nanocomposites with a loading of (B) 10, (C) 20, (D) 30 and (E) $40 \mathrm{wt} \%$, obtained from UV-vis DRS spectra by plotting $(\alpha \mathrm{h} v)^{2}$ vs. h $\nu$. 
S5. The formulas used for the calculation of permittivity $\left(\varepsilon^{\prime}\right)$, imaginary permittivity $\left(\varepsilon^{\prime \prime}\right)$ and dielectric loss tangent $(\tan \delta)$

The formulas used for the calculation of permittivity $\left(\varepsilon^{\prime}\right)$, imaginary permittivity $\left(\varepsilon^{\prime \prime}\right)$ and dielectric loss tangent $(\tan \delta)$ are expressed as the eqns (S1), (S2) and (S3), respectively.

$$
\begin{gathered}
\varepsilon^{\prime}=\frac{t \mathrm{C}_{p}}{\pi(\mathrm{d} / 2)^{2} \varepsilon_{0}} \\
\varepsilon^{\prime \prime}=\frac{t}{2 R(d / 2)^{2} \pi^{2} f \varepsilon_{0}} \\
\tan \theta=\frac{\varepsilon^{\prime}}{\varepsilon^{\prime \prime}}
\end{gathered}
$$

where $\mathrm{C}_{\mathrm{p}}, t, d$, and $R$ represent the capacitance, thickness diameter and resistance of the sample, respectively. The $f$ stands for the frequency, and $\varepsilon_{0}$ is the permittivity of vacuum $\left(8.85 \times 10^{-12} \mathrm{~F} \mathrm{~m}^{-1}\right)$.

S6. Imaginary permittivity $\left(\varepsilon^{\prime \prime}\right)$ as a function of frequency for pure PANI and BaFe ${ }_{22} \mathrm{O}_{19} / \mathrm{PANI}$ nanocomposites.

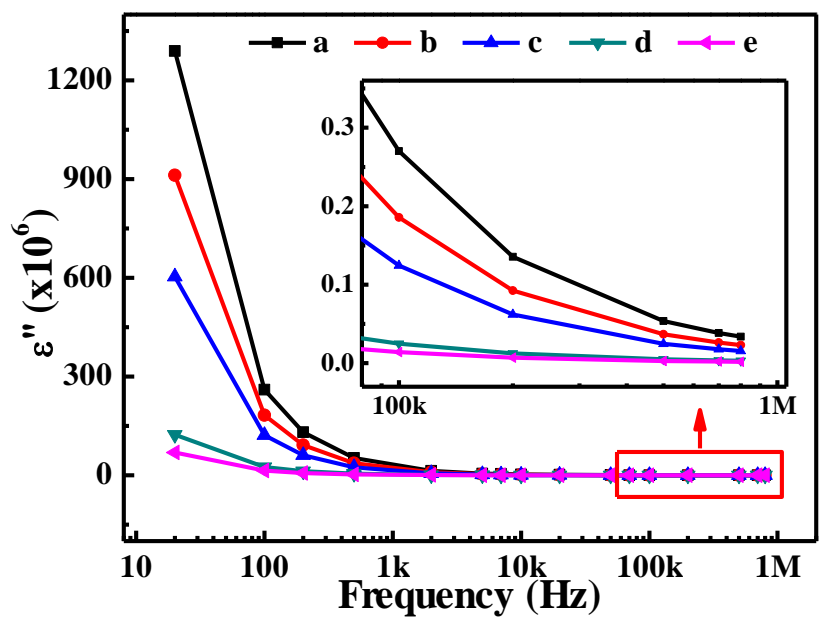

Figure S5. Imaginary permittivity $\left(\varepsilon^{\prime \prime}\right)$ as a function of frequency for (a) pure PANI, and $\mathrm{BaFe}_{12} \mathrm{O}_{19} / \mathrm{PANI}$ nanocomposites with a loading of (b) 10 , (c) 20, (d) 30 , and (e) $40 \mathrm{wt} \%$. 
S7. Resistivity vs temperature, $\ln (\mathrm{R})-\mathrm{T}^{-1}$ plotted within temperature range of $180-290$ $K$, and $\ln (\sigma)-T^{-1 / 4}$ curves of pure PANI
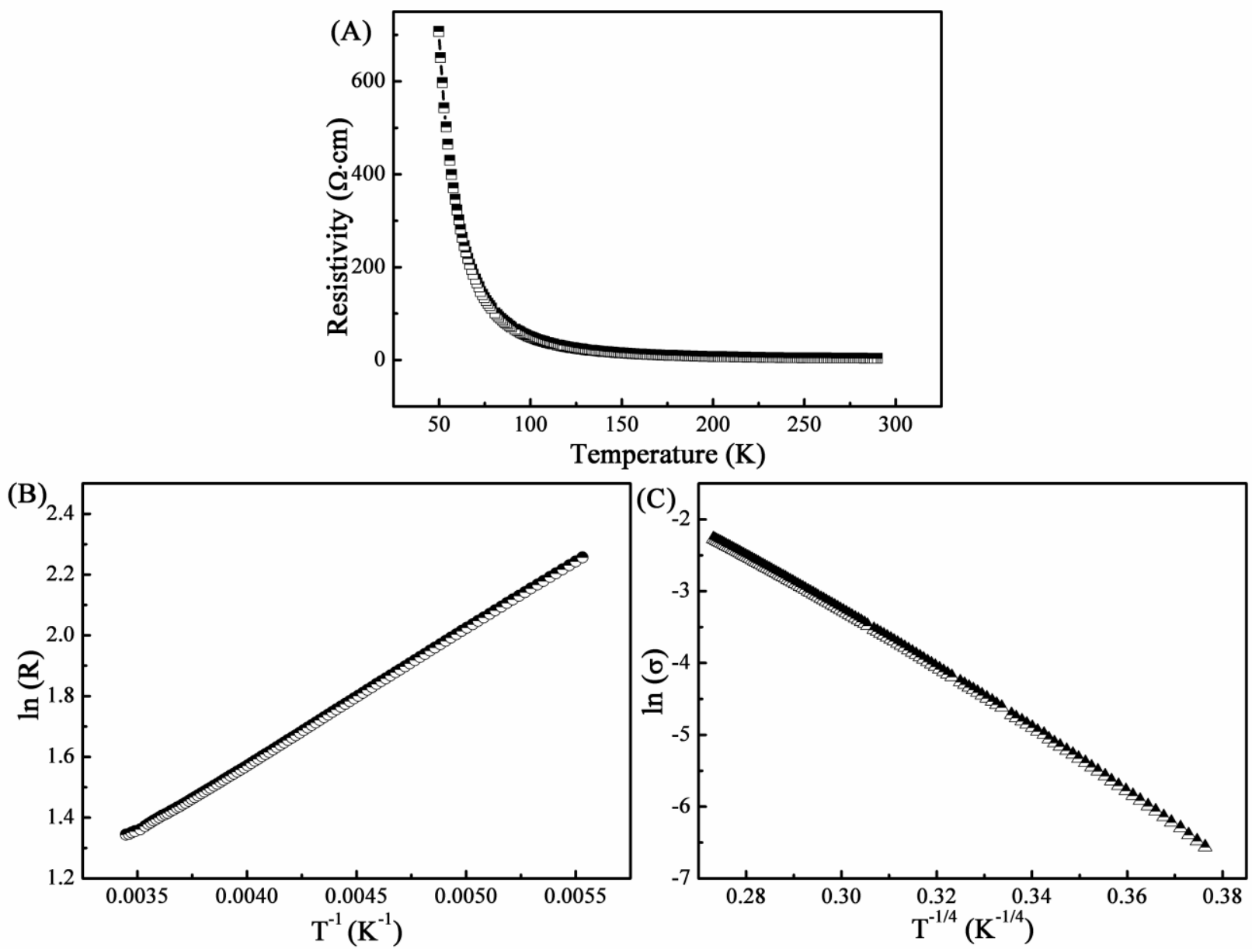

Figure S6. (A) Resistivity vs temperature, (B) $\ln (\mathrm{R})-\mathrm{T}^{-1}$ plotted within temperature range of $180-290 \mathrm{~K}$, and $(\mathrm{C}) \ln (\sigma)-\mathrm{T}^{-1 / 4}$ curves of pure PANI 
S8. Temperature dependent resistivity at different magnetic fields in 30 wt $\%$ $\mathrm{BaFe}_{12} \mathrm{O}_{19} / \mathrm{PANI}$ nanocomposites

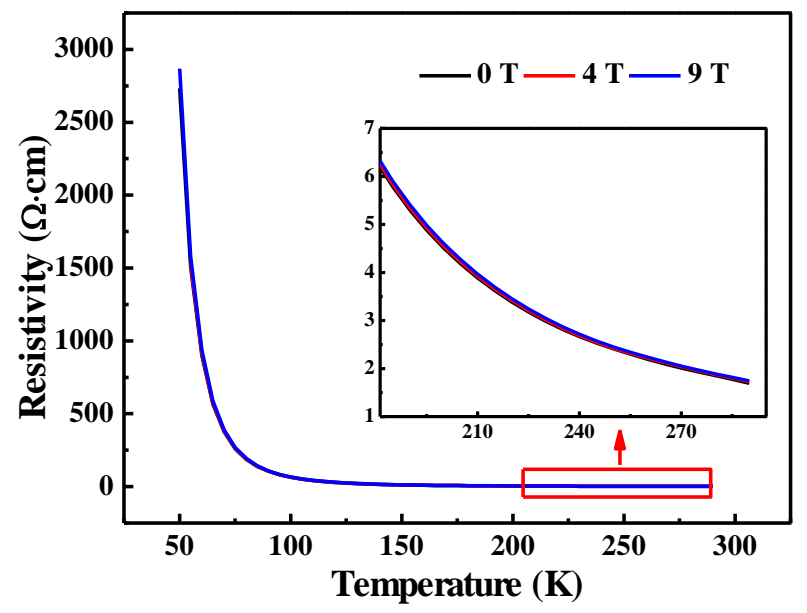

Figure S7. Temperature dependent resistivity at different magnetic fields of 0T, 4T and 9T in $\mathrm{BaFe}_{12} \mathrm{O}_{19} / \mathrm{PANI}$ nanocomposites with a loading of $30 \mathrm{wt} \%$.

\section{S9. Room temperature magnetoresistance of pure PANI}

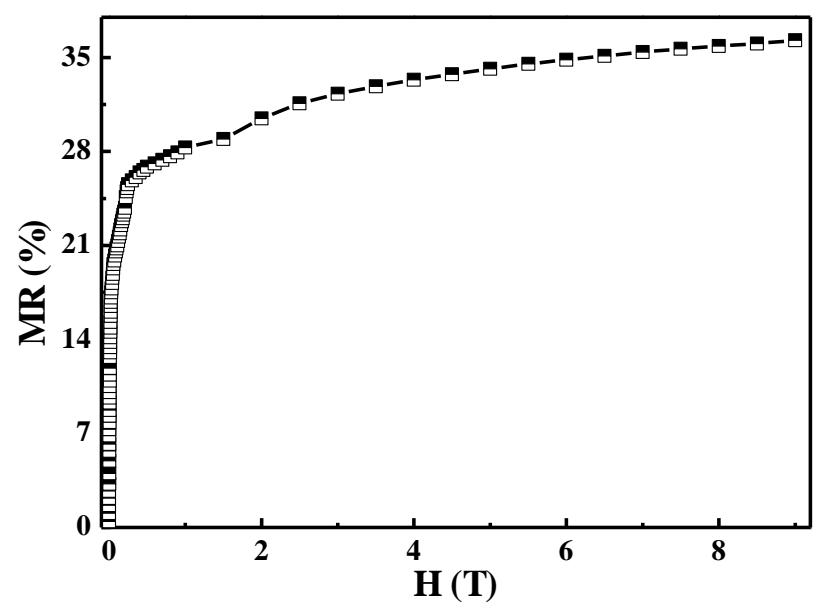

Figure S8. Room temperature magnetoresistance of pure PANI. 
S10. Calculated $a_{0}$ from forward interference model

Table S1. Calculated $a_{0}$ from forward interference model.

\begin{tabular}{lllll}
\hline & \multicolumn{4}{c}{$a_{0}(\mathrm{~nm})$} \\
\cline { 2 - 5 } $\begin{array}{l}\text { Magnetic } \\
\text { fields (T) }\end{array}$ & $10 \mathrm{wt} \%$ & $20 \mathrm{wt} \%$ & $30 \mathrm{wt} \%$ & $40 \mathrm{wt} \%$ \\
& $\mathrm{BaFe}_{12} \mathrm{O}_{19} / \mathrm{PANI}$ & $\mathrm{BaFe}_{12} \mathrm{O}_{19} / \mathrm{PANI}$ & $\mathrm{BaFe}_{12} \mathrm{O}_{19} / \mathrm{PANI}$ & $\mathrm{BaFe}_{12} \mathrm{O}_{19} / \mathrm{PANI}$ \\
\hline 0.1 & 1545 & 785 & 1069 & 1476 \\
0.5 & 2841 & 1460 & 1881 & 2574 \\
1.0 & 3387 & 1611 & 2165 & 2961 \\
2.0 & 4418 & 1608 & 2791 & 3792 \\
4.0 & 5280 & 1999 & 3348 & 4469 \\
6.0 & 5853 & 2200 & 3699 & 4849 \\
8.0 & 6142 & 2281 & 3963 & 5170 \\
\hline
\end{tabular}

